\title{
Hybrid 320 Ton Off Highway Haul Truck: Quarterly Technical Status Report 13, DOE/AL68080-TSR13
}

This thirteenth quarterly status report for the Hybrid Off Highway Vehicle (OHV) project, DOE Award DE-FC04-02AL68080 presents the project status at the end of December 2005, and covers activities in the thirteenth project quarter, October 2005 - December 2005.

\section{Project Management}

The current contractor, Dwight McCormick, is working out very well. After two months of work at Erie, PA, Dwight traveled to the Komatsu Proving Grounds. Support from GE Global Research staff has also assisted.

Initial discussions with Samuel Taylor at Department of Energy have suggested the program will require a no-cost extension to be filed, with a completed system validation by mid-2006. In addition, life testing and studies of the batteries on board could continue through 2006, also as a no-cost extension to the project. A detail application will be submitted in the first quarter of calendar year 2006.

\section{Technical Status}

\section{Full-scale testing}

Full-scale testing will begin next quarter. Final hurdles of EHS (Environmental, Health and Safety) need to be addressed and final software code tested. Prototype hardware is assembled and several subsystems of the full-scale prototype have been checked out.

\section{Truck Integration}

The hybrid control group was received, populated, wired and tested in Erie, PA. The group was shipped to the Komatsu Proving Grounds and installed on the vehicle. Reinforcing members for the truck are awaiting parts fabrication. The inductors and other components have been shipped to the proving grounds. Initial modifications to the existing truck power electronics group have been performed.

Komatsu has released drawings for the hybrid control group support members and the inductor supports. Drawings for upper deck modifications and front bumper mounting are in progress.

Vibration isolation selection has been completed after a review of vibration data and isolator performance curves. High deflection mounts from Barry Controls were selected and put into the mounting design. Design changes regarding mounting holes have been communicated to Komatsu and accepted.

\section{Battery Life testing}

MES-DEA, manufacturer of the ZEBRA battery, has been actively testing ZEBRA cells, as they will be applied in the system validation. Two operating points are being investigated: a nameplate operating point, and a high charge power operating point. The test measures charge resistance and discharge resistance at critical portions of the profile. Resistance rise will be the dominant factor in determining useful life of the battery system. Excessive resistance will limit the power rating of the system and generate excessive heat causing decreased hybrid benefits and thermal failures of cells.

The normal operating point utilizes the ZEBRA battery at $32 \mathrm{~kW}$ per Z12 for $384 \mathrm{~kW}$ total hybrid system power. The test applies the power we expect to see from the Proving Ground route as calculated by GE's mission analysis model. The test has been stopped in October after cell resistances began to climb and diverge. A total of 1365 nameplate cycles (18750 OHV cycles, or about 12 months time) were completed before ending the test. 